\title{
Non-Covalent Immobilization of Chiral (Salen) Complexes on HF-treated Mesoporous MFI-type Zeolite for Asymmetric Catalysis
}

\author{
Kwang-Yeon Lee, Choong-Young Lee, and Geon-Joong Kim${ }^{-}$ \\ Department of Chemical Engineering. Inha Linversity, Incheon $402-751$, Korea. ${ }^{\times}$-mail: kimglainha ac.kr \\ Department of Chemical Enwironmental Technologv. Inha Technical College. Incheon $402-752$, Korea \\ Recened October 9, 2008, Accepted December 24, 2008
}

\begin{abstract}
MFI structural zeolite (ZSM-5 or Sililcalite) was treated with HF solution to introduce mesoporous channels in the microporous cry'stals. Inner mesopore size could be controlled from 2.5 to $3.5 \mathrm{~nm}$ by changing the concentration of HF solution. The pore structure of HF-treated MFI zeolite was studied by instrumental analysis. The active Co (III) salen complex monomers were successfully anchored non-covalently on the surfaces of mesoporous MFI-type zeolite. These heterogeneous catalysts could be applied in asymmetric ring opening of terminal epoxides by phenol derivatives. It showed very high enantioselectivity and yield up to $95 \%$ in the catalytic synthesis of optically active a-aryloxy alcohol compounds.
\end{abstract}

Key Words: Mesoporous MFI. HF, Chiral (salen) complex. Non-covalent attaclument. Asymmetric catalysis

\section{Introduction}

Terminal epoxides are one of the important subclasses for the organic synthesis.' As a consequence. the preparation of optically pure terminal epoxides has long stood as a significant target for the asymmetric synthesis of chiral buildingblock. ${ }^{2}$ The catalytic ring opening reaction provides a practical manner to prepare stereochemically enriched terminal epoxides. ${ }^{3.4}$ It was found that several systems based on the chiral cobalt-salen complexes are very efficient for the highly enantioselective kinetic resolution of terminal epoxides by phenolic nucleophiles. These active and selective salen-based homogeneous catalysts are appearing as candidates for heterogenization onto the polymer or inorganic supports. It is well known that the heterogeneous cataly'sts can offer the practical advantages in the facile separation of products. as well as simple recovery and reuse of catalysts. ${ }^{\$ 6}$ Various strategies have been explored and developed to enhance the catalytic efficiency of heterogenized salen complexes. Some approaches were demonstrated successfully to date in the asymmetric catalysis by using dimeric, ${ }^{5}$ dendrimeric. ${ }^{6}$ polymeric $^{7.8}$ and supported-type catalysts. ${ }^{3}$ Over the last two decades, salen complexes have been successfully synthesized inside the supercages of X. Y. EMT zeolites. ${ }^{13.14}$ However the pore size and cage shape of microporous zeolites are strictly limited by their crystalline topology (usually $<1.5 \mathrm{rm}$ ) for other zeolites such as MFI. ${ }^{15-1}$ ' It is difficult to introduce the salen complexes with relatively larger molecular size into the microporous channel of zeolites. The development of simple method to synthesize the zeolites having well defined mesopores still remains as a challenging objective. Compared with microporous zeolites. mesoporous ones have larger size pore and cage, which provide possibilities for trapping larger molecules and more comfortable microenvironment for giest molecules. ${ }^{15.19}$

In this work. a method to obtain the novel mesoporous MFI structural zeolites with tunable pore size and well defined shape was examined and presented. Our main methodology for synthesis of mesoporous MFI was desilication of microporous MFI-zeolite by HF solution treatment. To our best knowledge. this method is most simple and efficient as compared to other procedures. In addition, herein we also report the asymmetric catalytic activities of chiral (salen) Co(III) conplex immobilized in the mesopores of modified ZSM- 5 by a non-covalent method. The obtained cataly'st was tested in the asymmetric ring opening of terminal epoxides. These heterogeneous chiral catalysts showed a high activity and selectivity in the enantioselective phenolic ring opening of terminal epoxides to synthesize valuable chiral intermediates such as beta-blockers.

\section{Experimental}

Synthesis of mesoporous MFI zeolite by HF treatment. Silicalite or ZSM-5 (Zeochem Ltd. Co.. Si/Al = 25) was treated by HF solution ( $50 \mathrm{wt} \%$ aqueous solution; Duksan Pure Chemicals $\mathrm{Co}$. Ltd.) with different concentrations (0.2. 0.4 and $0.6 \mathrm{~g}-\mathrm{HF} /(\mathrm{g}-z e o l i t e))$ at room temperature for $1 \mathrm{~h}$. The corresponding HF solution was added very slowly for $30 \mathrm{~min}$. The solid sample was recovered by filtration and washed by hot deionized water. It was dried in oven at $120^{\circ} \mathrm{C}$ for overnight before use. The yields of recovered mesoporous ZSM-5 zeolites were $90 \mathrm{wt} \% .81 \mathrm{wt} \%$ and $75 \mathrm{wt} \%$ relative to the starting solid amount. respectively, when $0.2,0.4$ and $0.6 \mathrm{~g}-\mathrm{HF}$ were treated per gram of zeolite.

Incorporation of aluminium into the mesoporous MFIzeolite. $\mathrm{AlCl}_{2}-6 \mathrm{H}_{2} \mathrm{O}$ was loaded on $\mathrm{HF}$-treated $\mathrm{ZSM}-5$ or Silicalite in the range of $10-30 \mathrm{wt} \%$ (Al basis), and the dried sample was calcined at 250 and $550^{\circ} \mathrm{C}$, respectively. The coordination of Al in the HF-treated ZSM-5 or Silicalite was characterized by ${ }^{27}$ Al-MAS-NMR analysis.

Chiral (Salen) cobalt complexes immobilized on mesoporous MFI-zeolite. The $\mathrm{HF}$ treated $\mathrm{Al}$-containing mesoporous materials were used as a support for immobilization of chiral (salen) cobalt complexes. The procedure to anchor the chiral complexes on the surfaces of mesoporous MFI is shown in 

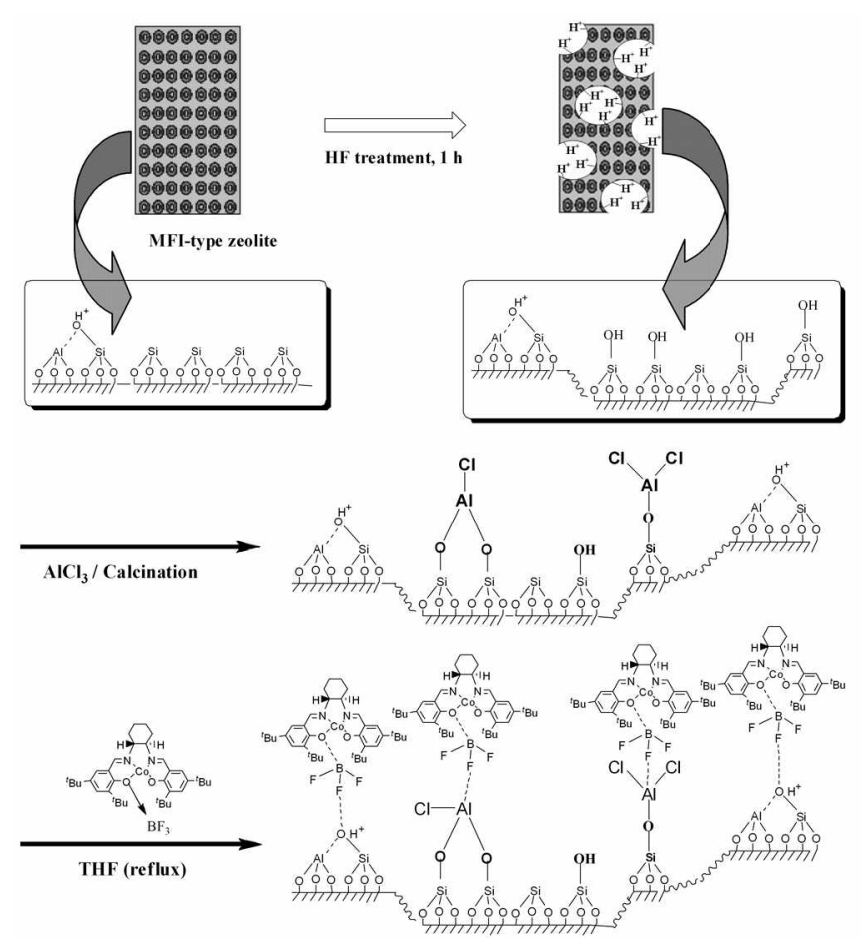

Scheme 1. Schematic illustration for the synthesis of the chiral Co-salen complex(B) immobilized on mesoporous MFI-zeolites.

Scheme 1. First. chiral Co (salen) complex (B) was prepared by mixing in a $1: 1$ mole ratio of $(R, R)-(-)-N_{,} N^{2}-b i s(3,5-$ di-tert-buty lsalicy lidene)-1.2-cyclohexanediaminocobalt(II) (A) and $\mathrm{BF}_{3} \cdot 2 \mathrm{H}_{2} \mathrm{O}$ under air for $4 \mathrm{~h}$ in the presence of methylene chloride (MC). Evaporation of $\mathrm{MC}$ gave a dark black solid (vield: $98 \%$ ). The stnicture of cobalt(II) salen complex (A) and chiral Co (salen) complex (B) is indicated in Scheme 2.

The heterogenized chiral salen catalysts were prepared by refluxing $\mathrm{HF}$ treated $\mathrm{Al}$-containing mesoporous $\mathrm{MFI}$ Leolites with the solution containing Co-salen complex (B) in $\mathrm{MC}$ for $2 \mathrm{~h}$. The heterogeniced complex with dark green color was obtained by filtration and sequential washing with MC. THF (tetrahedrofuran) and methanol until the filtrate was colorless. The catalyst was dried in vacto to yield a heterogenized $\mathrm{Co}$ (salen) complex.

Characterization. The phase stnicture of parent or HFtreated mesoporous ZSM-5 and Silicalite was determined by $\mathrm{X}$-ray powder diffraction analysis (Phillips PW22XX and Rigaku DMAX 2500 diffractometer with $\mathrm{CuK} \alpha$ radiation). The morphology and microstructures of as-prepared samples were characterized by field emission transmission electron microscopy (FE-TEM. S-4200), and field emmission scanning electron microscopy (FE-SEM, JEM-2100F). The nitrogen adsorption/desorption analysis was perforned at $-196^{\circ} \mathrm{C}$ by using a surface area and porosity analyzer equipment (Micromeritics. ASAP 2010). The sample was outgassed at $10^{-5}$ torr and $200{ }^{\circ} \mathrm{C}$ prior to measurement. The specific surface areas were calculated according to BET theory. and the mean pore size was determined by BJH analysis. FT-IR spectra were recorded on a BRUKER IFS 48 spectrometer.

Genenal procedure for the catalytic reaction. In a repre-

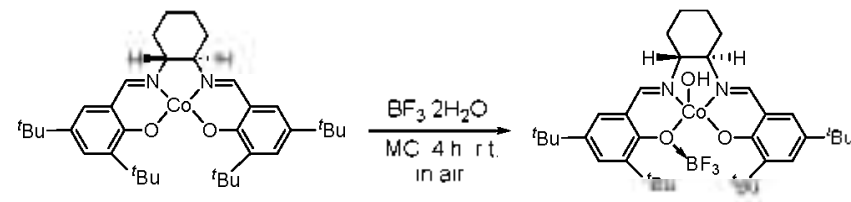

Chiral Co(II) salen (A)

Co-salen complex (B)

Scheme 2. 'l he structure of the cobalt salen complexes.

sentative reaction between epichlorohydrin (2-(clloromethyl) oxirane; $\mathrm{ECH}$ ) and phenol derivative. the catalyst ( $1.0 \mathrm{~mol} \%$ salen-loading/support). tert-butyl methyl ether (TBME) and $( \pm)-E C H(0.93 \mathrm{~g}, 10 \mathrm{mmol})$ were charged in an oven dried 25 $\mathrm{mL}$ flask and the reaction mixture was stirred in open atmosphere at ambient temperature. After addition of phenol $(0.42$ g. $4.5 \mathrm{mmol} 0.45$ equiv). the resultant mixture was stirred for $60 \mathrm{~h}$, and the conversion of phenol and ee \% (enantiomeric excess \%) values of the ring opened product were deternined by GC using a capillary chiral column (CHIRALDEX. $\gamma$ cyclodextrin trifluroacetyl. $20 \mathrm{~m} \times 0.25 \mathrm{~mm}$ i.d.) and by HPLC using a Chiralcel $\mathrm{B}$ OD-H column $(24 \mathrm{~cm} \times 0.46 \mathrm{~cm})$.

\section{Results and Discussion}

Crystallinity of HF-treated MFI-zeolites. X-ray diffraction analysis was carried out to investigate the structural changes in MFI-zeolite upon acid treatment. HF dissolves the silica in the ceolite crystal so fast that a careful and controlled treatment is needed to introduce the mesoporous clanels in the zeolitic crystal. HF treated MFI-zeolite (Silicalite and ZSM-5) exhibits the almost same diffraction pattem as compared to that of the untreated original zeolite. The decrease of peak intensity was not severe even with increasing the HF concentration.

FE-SEM images. The FE-SEM images for representatives of HF-treated MFI-zeolite and the parent zeolites are shown in Fig. 1. The morphological changes of zeolite during the HF treatment have not appeared quite crucial. As shown in Fig. 1. no deep corrosion of surfaces was observed in the samples after treatment of MFI zeolites with $0.6 \mathrm{~g}-\mathrm{HF} / \mathrm{g}$-zeolite). After complete reaction of HF with silica in the zeolites, the added amount of $0.6 \mathrm{~g}-\mathrm{HF}$ is equivalent to the dissolution of $23 \mathrm{wt} \%$ silica in starting Silicalite. based on the reaction $\left(\mathrm{SiO}_{2}\right.$ $+4 \mathrm{HF}=\mathrm{SiF}_{4}+2 \mathrm{H}_{2} \mathrm{O}$ ). The experimentally recovered yield of sample was about $75 \mathrm{wt} \%$ after $0.6 \mathrm{~g} \mathrm{HF} / \mathrm{g}$-silicalite treatment. and this value is well mached to the calculated one. Even under the high degree of desilication up to $23 \mathrm{wt} \%$ from MFI zeolite, the crystal morphology of MFI zeolite was almost similar before and after HF treatment. as can be seen in the result of SEM analysis (Fig. 1). This reveals that the silica dissolution by HF has happened selectively at the inside of zeolite particles. because the crystal size of ZSM-5 or Silicalite has not changed so much after dissolution of silica in the zeolites. However, the formation of mesopore inside the MFI-zeolite was not clear by SEM investigation. As a result, additional FE-TEM and BET analyses for the samples were needed to confirm the formation of mesoporosity inside HF-treated zeolites.

FE-TEM images. To investigate the formation of mesopore 

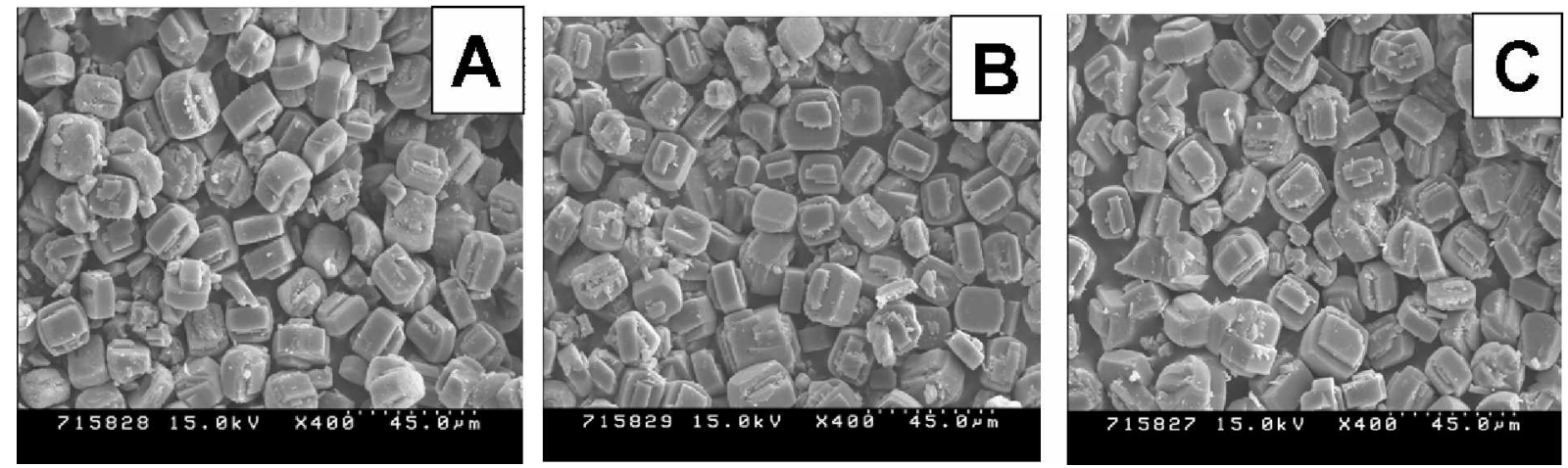

Figure 1. SEM images of (A) Original Silicalite; (B) $0.2 \mathrm{~g}-\mathrm{HF} /(\mathrm{g}-\mathrm{ze}$ lite) treated Silicalite: (C) $0.6 \mathrm{~g}-\mathrm{HF} / \mathrm{g}$-zeolite) treated Silicalite.

channels in the MFI zeolite after HF treatment. TEM analy sis was performed and the obtained images are summarized in Fig. 2. The parent MFI-zeolite showed no mesopores within the microporous crystal for both cases of Silicalite and ZSM-5. Many mesopores inside the microporous MFI-zeolite crystal were formed under the HF concentration from 0.2 to $0.6 \mathrm{~g}-\mathrm{HF} /$ (g-zeolite). TEM photograph shows clearly that the mesopore is formed by the HF solution treatment. The range of pore size inside the microporous MFI-zeolite crystal was changed from about 2.5 to $3.5 \mathrm{~mm}$ (Fig. 3B-3D). The pore size of mesoporous MFI zeolite was increased by increasing the concentration of HF solution. Hence. HF treatment yields mesopores in MFI-zeolite, and the pore developments and structures are dependent on the HF concentration.

Nitrogen adsontion/desontion. For further investigation of the mesopore formation after HF-treatment, nitrogen adsorption experiment was performed. Fig. 3 shows the nitrogen adsorption/ desorption isotherms of the HF-treated MFI-zeolite as well as the parent zeolites. The nitrogen adsorption isotherms of parent microporous zeolites were basically of IUPAC type I (Fig. 3A and 3E). The predominant adsoption ended below $P P_{0}=0.02$. which is characteristic of uniform microporous solids. HF-treated MFI-zeolites showed the different adsorption/desorption characteristics. Compared to parent zeolites. all isotherms of HF treated zeolites showed the increase in uptake of nitrogen and the change in the shapes of hystesis loops extending from $P: P_{0}=0.2-1$. indicating that the mesopores have been created upon HF treatments. In these cases. the shape of hystesis loops showed the type IV adsorp- tion/desorption isotherm. Combined with the images of FETEM (Fig. 2). it is suggested that slit-shaped or ink-bottlelike mesopores were formed mainly at the boundary portion of MFI-zeolite surfaces to bulk.

There are many vacant tetrahedral sites and $\mathrm{OH}$ silanol groups which were generated after desilication of zeolite by HF. We examined the incorporation of aluminium into the zeolite framework after HF-treatment to use as a support for anchoring the chiral salen complexes. The Co (salen) complexes (B) having $\mathrm{BF}_{\underline{3}}$ group in the structure (in Scheme 1) are easily attached onto the hydronium ions such as Bronsted acidic solids. To test the incorporation of aluminium ions into the zeolite framework. $\mathrm{AlCl}_{5}-6 \mathrm{H}_{2} \mathrm{O}$ was impregnated on $\mathrm{HF}$-treated ZSM-5 or Silicalite in the range of $10-30 \mathrm{wt} \%$ (Al basis). and the dried sample was calcined at $550^{\circ} \mathrm{C}$. The nitrogen adsorption isothenns of those samples were detennined to imvestigate whether the mesopore channels are blocked by $\mathrm{Al}$ species. As can be seen in Fig. 4(D) and (H). it is clear that the mesoporosity of MFI zeolite was maintained after loading of $20 \mathrm{wt} \% \mathrm{AlCl}_{3}-6 \mathrm{H}_{2} \mathrm{O}$ and calcination at $550^{\circ} \mathrm{C}$ in air without blocking by $\mathrm{Al}_{2} \mathrm{O}_{3}$ in the mesopore channels. The shape of nitrogen adsorption isotherms are same before and after impregnation of aluninium sources.

Pore stnuctural parameters of HF-treated MFI-zeolite and parent zeolites are shown in Table 1 . The changes in the surface area. pore size and pore volume of HF-treated MFI-zeolites are also shown in Table 1 as well as in Fig. 4, depending on the concentrations of adopted HF solution. The treatment of the MFI zeolite with $0.2 \mathrm{~g} \sim 0.6 \mathrm{~g}-\mathrm{HF} /(\mathrm{g}-z e o l i t e)$

Table 1. Pore structural parameters of HF-treated MFI-zeolites and parent zeolite

\begin{tabular}{|c|c|c|c|c|c|c|}
\hline Entry & $\begin{array}{l}\text { Parent } \\
\text { zeolite }\end{array}$ & $\begin{array}{l}\mathrm{HF} \text { concentration } \\
\text { (g-HF/g-zeolite) }\end{array}$ & \multicolumn{2}{|c|}{ Specific surface area $\left(\mathrm{m}^{2} / \mathrm{g}\right)$} & $\begin{array}{l}\text { Pore volume } \\
\left(\mathrm{cm}^{3} / \mathrm{g}\right)\end{array}$ & $\begin{array}{c}\text { Averaged Pore size } \\
(A)\end{array}$ \\
\hline 1 & Silicalite & No treatment & 386.5 & 0 & 0.19 & 6 \\
\hline 2 & Silicalite & $0.2 \mathrm{~g}-\mathrm{HF}$ & 255.3 & 225.5 & 0.22 & 23.4 \\
\hline 3 & Silicalite & $0.6 \mathrm{~g}-\mathrm{HF}$ & 235.4 & 247.6 & 0.23 & 25.7 \\
\hline 4 & Silicalite & $0.6 \mathrm{~g}-\mathrm{HF}^{a}$ & 230.1 & 241.2 & 0.23 & 24.0 \\
\hline 5 & H $\angle S M-5$ & No treatment & 314.8 & 0 & 0.17 & 6 \\
\hline 6 & $\mathrm{H} \angle \mathrm{SM}-5$ & $0.2 \mathrm{~g}-\mathrm{HF}$ & 220.9 & 169.7 & 0.19 & 35.1 \\
\hline 7 & H $\angle S M-5$ & $0.6 \mathrm{~g}-\mathrm{HF}$ & 213.2 & 192.5 & 0.20 & 33.6 \\
\hline 8 & HZSM-5 & $0.6 \mathrm{~g}-\mathrm{HF}^{a}$ & 211.6 & 190.1 & 0.19 & 33.2 \\
\hline
\end{tabular}

"20 $\mathrm{wt}^{\circ}{ }_{0} \mathrm{AlCl}_{2}$ was impregnated after $\mathrm{HF}$ treatment, and the sample was calcined at $550^{\circ} \mathrm{C}$ 

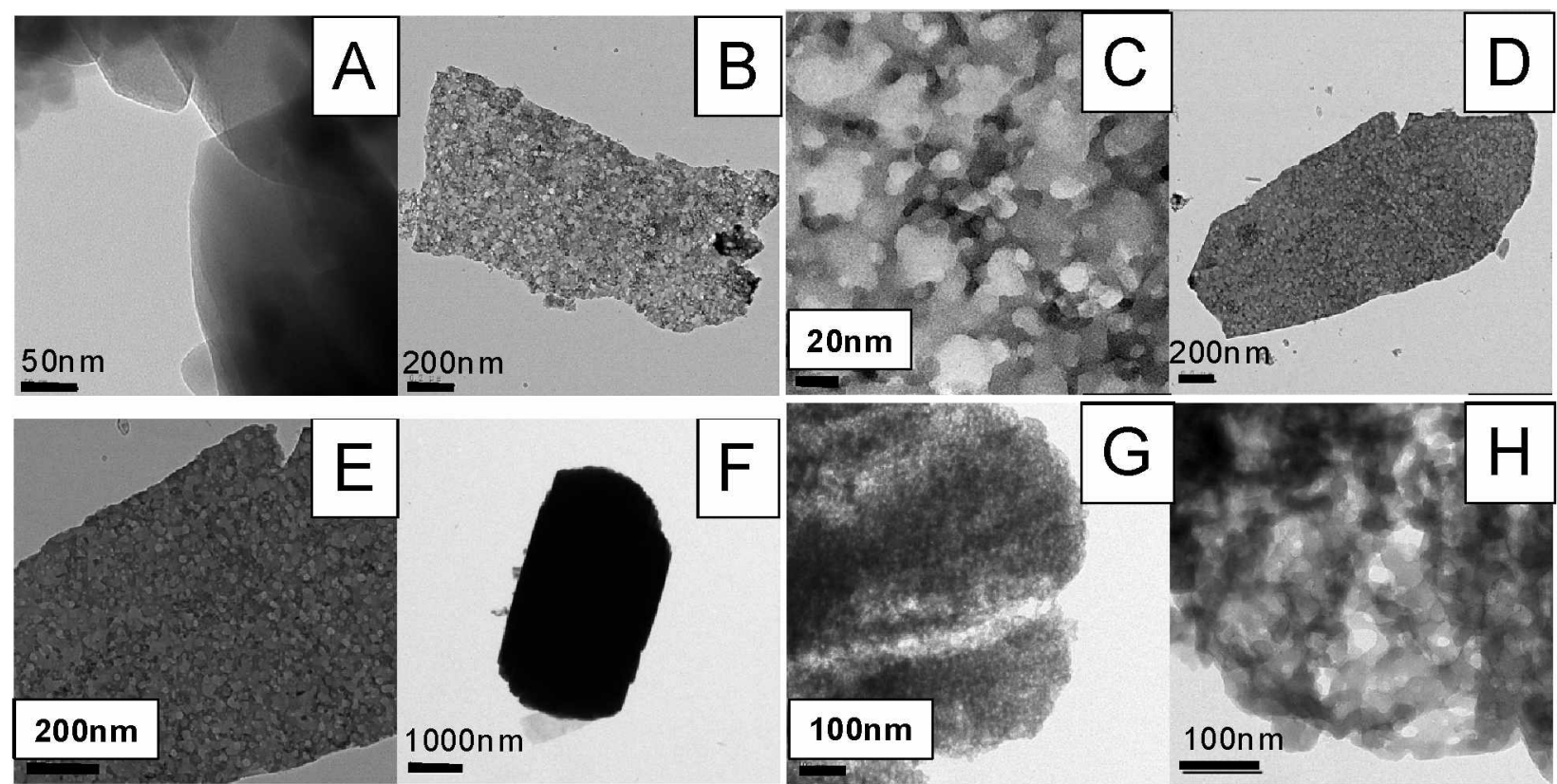

Figure 2. TEM images of (A) original Silicalite; (B) $0.2 \mathrm{~g}-\mathrm{HF} /$ (g-zeolite) treated Silicalite(low resolution); (C) sample(B) in high resolution; (D) $0.6 \mathrm{~g}-\mathrm{HF} /(\mathrm{g}$-zeolite) treated silicalite(low resolution): (E) sample(D) un high resolution; (F) ongmal HZSM-5; (G) $0.2 \mathrm{~g}-\mathrm{HF} /(\mathrm{g}-\mathrm{zeol}$ (te) treated HZSM-5: $(\mathrm{H}) 0.6 \mathrm{~g}-\mathrm{HF} /(\mathrm{g}$-zeolite $)$ treated HZSM-5.

condition caused significant changes in the surface area. pore size and pore volume. The large surface area. pore volume and big pore size were formed by the treatment of $0.6 \mathrm{~g} \cdot \mathrm{HF} /$ (g-zeolite) due to the desilication process of MFI-zeolite. Adsorption capacity of the sample was increased with the increasing the total $\mathrm{HF}$ amount added to modify the zeolites.

The coondination of Aluminium in the mesoporous MFIzeolite. The chiral Co (salen) complex (B) contains fluorine atoms as shown in Scheme 2. In this work. the homogenous chiral $\mathrm{Co}(1 \mathrm{ll})-\mathrm{BF}_{3}$ salen catalyst (B) was synthesized by the oxidation of $\mathrm{Co}$ (II) to $\mathrm{Co}$ (III) species in the presence of $\mathrm{BF}_{y}$. $2 \mathrm{H}_{2} \mathrm{O}$ under the aerobic condition as shown in Scheme 2. The
UV. FT-IR, ESCA, and NMR. analyses have been performed to detennine the structure of synthesized cobalt-salen catalysts and the result was reported previously. ${ }^{20}$ ESCA (electron spectroscopy for chemical analysis) was used to analyze and identify the structural changes created by the addition of $\mathrm{BF}_{3} \cdot 2 \mathrm{H}_{2} \mathrm{O}$ to the salent-type complex. For chiral $\mathrm{Co}(\mathrm{III})-\mathrm{BF}_{3}$ salen (B). the change of oxidation state of starting $\mathrm{Co}^{2+}$ in the salen complex to $\mathrm{Co}^{3+}$ after treatment of $\mathrm{BF}_{3} \cdot 2 \mathrm{H}_{2} \mathrm{O}$ was confirmed by ESCA analysis as compared with the $\mathrm{CO}^{\mathrm{II}}-\mathrm{OAC}$ Jacobsen catalyst and the [Co ${ }^{\text {II }}$ (salen)]-type complex (A) as reference samples. In addition, binding energies of oxygen in the salen complex also changed after introduction of $\mathrm{BF}_{2}$
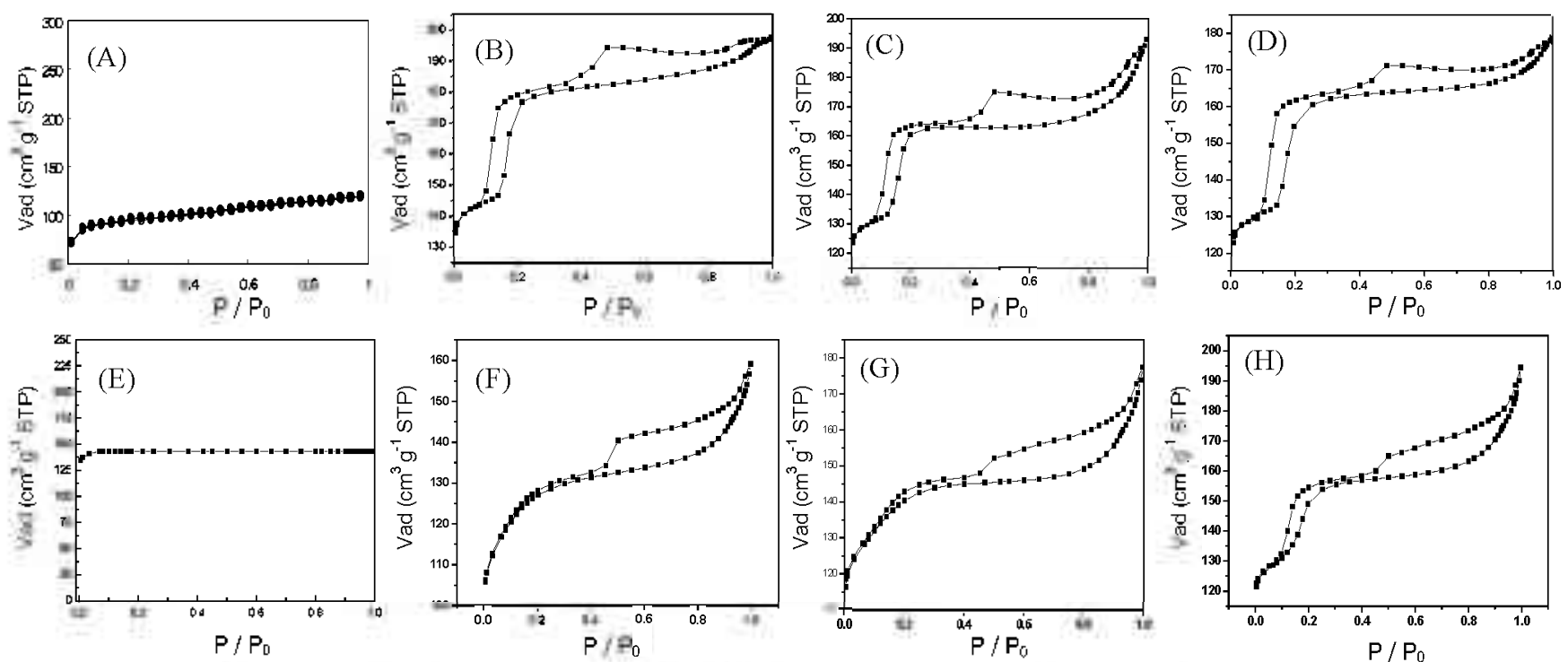

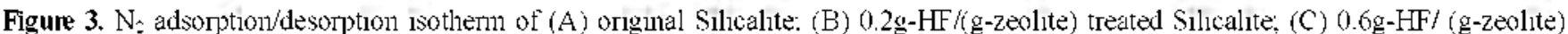
treated Silicalite (D) $0.6 \mathrm{~g}-\mathrm{HF} /\left(\mathrm{g}-\mathrm{zeolite}\right.$ ) treated and $20 \mathrm{wt} \%$ Al-loaded Silicalite (calcined at $550^{\circ} \mathrm{Cl}$; (E) original $\mathrm{HZSM}-5$; (F) $0.2 \mathrm{~g}-\mathrm{HF} /$ (g-zeolite) ZSM-5; (G) $0.6 \mathrm{~g}-\mathrm{HF} /(\mathrm{g}-\mathrm{zeolite}$ ) treated ZSM-5; and $(\mathrm{H}) 0.6 \mathrm{~g}-\mathrm{HF} /(\mathrm{g}$-zeolite) treated and 20 w \% Al-loaded ZSM-5 (calcined at $55 \mathrm{C}$ (C) 


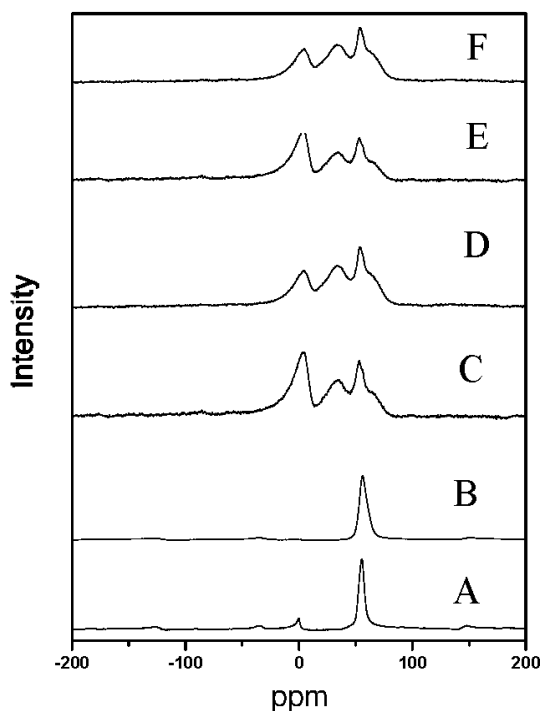

Figure 4. ${ }^{27}$ Al MAS NMR spectra of (A) Original HZSM- $-5(\mathrm{Si} / \mathrm{Al}=$ 25): (B) 0.6g-HF/(g-zeolite) treated HZSM-5: (C) $0.6 \mathrm{~g}-\mathrm{HF} /$ (g-zeolite) treated and $30 \% \mathrm{AlCl}_{2}$ loaded HZSM-5 $\left(250^{\circ} \mathrm{C}\right.$ dry $)$ (D) $0.6 \mathrm{~g}$ $\mathrm{HF} /\left(\mathrm{g}\right.$-zeolite) treated and $30 \% \mathrm{AlCl}_{3}$ loaded HZSM-5 (calcined at $550{ }^{8} \mathrm{C}$ ): (E) $0.6 \mathrm{~g}-\mathrm{HF} /(\mathrm{g}$-zeolite) treated and $30 \% \mathrm{AlCl}$ loaded Silicalite $\left(250{ }^{\circ} \mathrm{C}\right.$ dry); (F) $0.6 \mathrm{~g}-\mathrm{HF} /(\mathrm{g}$-zeolite) treated and $30 \%$ $\mathrm{AlCl}_{3}$ loaded Silicalite (calcined at $550^{\circ} \mathrm{C}$ ).

indicating that $\mathrm{BF}_{3}$ has coordinated to the oxygen of salen by the Lewis acidic action. Furthermore, the chiral Co(III)- $\mathrm{BF}_{3}$ salen complex (B) showed the absorption peak for hydroxyl group over $3600 \mathrm{~cm}^{-1}$ in FT-IR analyses after full drying. proposing $\mathrm{Co}(\mathrm{III})-\mathrm{BF}_{3}$ salen posses $\mathrm{OH}$ group in the structure as depicted in Scheme 2.

These Co (salen) complexes (B) were easily attached onto the acidic sites of supports and they were adhered strongly to the solid surfaces even after washing with various polar solvents. The $\mathrm{SiO}_{-}-\mathrm{Al}_{2} \mathrm{O}_{3}$ having Bronsted acid sites mainly can anchor the Co (salen) complex (B) in a large amount. We believe this unique immobilization is due to the adsorption of the complex on to the acidic sites of support through the hydrogen-bonding. However. the adsorption of Co (salen) complexes (B) on the Lewis acid sites of aluminium present on the support can not be ruled out as indicated in Scheme 2. since $\mathrm{Co}$ (salen) complexes (B) were also attached strongly to $\mathrm{SiO}_{2}$ on which $\mathrm{AlCl}_{3}$ was impregnated and calcined. They could not be anchored on the pure $\mathrm{SiO}_{2}$.

Because the molecular size of Co (salen) complex (B) is bigger than the pore size of MFI type zeolites. the parent microporous ZSM-5 zeolite. except HF-treated one, could not adsorb the complex (B) at all. Especially. Silicalite has no capability to immobilize the salen complex, since it contains no aluminum ion in the strnicture to generate acidic sites. In general. the silanol nest formed by the desilication of MFI type zeloite framework. and the heteroatomes can be re-introduced into that position surrounding with four silanols va isomorphous substitution. Hyun ef al. have applied the impregnation method of $\mathrm{AlCl}_{3}-6 \mathrm{H}_{2} \mathrm{O}$ to generate the acidic sites on the mesoporous silica. ${ }^{21}$ In this work, we tried to incorporate the aluminum ions into the structure of mesoporous MFI-zeolites after HF treatment. The coordination of alumina was measured by ${ }^{2 ?} \mathrm{Al}-\mathrm{MAS}-\mathrm{NMR}$ analysis after $\mathrm{Al}$ loading and calcination.

Fig. 4 shows the Al-MAS-NMR spectra of original HZSM-5. HF-treated mesoporous HZSM-5 and Al-incorporated mesoporous MFI zeolites after HF-treatment. There are two distinct peaks on the ${ }^{27}$ Al-MAS-NMR spectra of original HZSM-5 (Fig. 4(A)): The strong peak at chemical shift of $60 \mathrm{ppm}$ is related to the framework aluminium atoms with tetrahadral coordination, and that peak at 0 ppm can be attributed to the non-framework aluminium.- After HF treatment the very sntall peak at 0 ppnt disappeared, showing that the non-framework aluminium species were washed out during the dissolution of silica in the zeolite (Fig. 4(B)). When $30 \mathrm{wt} \%$ of $\mathrm{AlCl}_{3}$ was impregnated on the mesoporous sample (B) and calcined at $250^{\circ} \mathrm{C}$, three distinct peaks on the Al-MAS-NMR spectra were found as in Fig. $4(\mathrm{C})$. The peak at chemical shift of $20 \mathrm{ppm}$ in "Al-MAS-NMR spectra is interpreted as 5-coordinated Al site: namely these aluminiums are surrounded by 4 oxygens in the framework and one water molecule in the non-framework position. ${ }^{2-}$ However, after loading of $\mathrm{Al}$ under that condition. both the framework and non-framewok aluminium were present. By calcination of that sample at increased temperature of $550^{\circ} \mathrm{C}$, the portion of tertahedral or 5-coordinated sites due to the incorporation of Al into the framwork of mesoporous zeolites has increased as compared to the non-framework sites (Fig. 4(D). This trend was also same in the case of HF-treated Silicalite. Because Silicalite has no Al sources. there is no peak found in the Al-MAS-NMR spectra. After loading of Al source. followed the calcination at $250{ }^{\circ} \mathrm{C}$. three peaks were found as shown in Fig. $4(\mathrm{E})$. The peak at 0 ppm related to the nonframework position has decreased after calcining the sample at $550{ }^{\circ} \mathrm{C}$ (Fig. $4(\mathrm{~F})$ ). From the results of ${ }^{2} \mathrm{Al}-\mathrm{MAS}-\mathrm{NMR}$ spectra, it is clear that the incorporation of $\mathrm{Al}$ into the framework sites can be aclieved successfully by the reaction between $\mathrm{AlCl}_{2}$ and $\mathrm{Si}(\mathrm{OH})_{x}$ formed on the surfaces of zeolite after HF treatment

FT-IR spectra. The heterogenized chiral Co-salen complexes present on the surfaces of mesoporous MFI-zeolite were characterized by FT-IR analy sis, and the result is shown in Fig. 5. As mentioned above the chiral (salen) cobalt(III) complex (B) can not be introduced into the microporous channel of starting MFI zeolite because of its large molecular size ( $\bar{a}$ 16 16 ). The microporous Silicalite(pore size; $5.5 \AA$ ) could not supply big size pores enough to introduce the chiral (salen) complexes inside of crystals. The characteristic peaks for homogeneous salen have appeared at the position of $2958-2950,2912,1612$ and $1535 \mathrm{~cm}^{-1}$ on IR spectra. However. the chiral (salen) cobalt(III) complex (B)-anchored mesoporous ZSM-5 (Fig. 5(B)) or Silicalite (Fig. 5(D)) has exhibited the similar absoprtion bands of the pure homogeneous chiral (salen) complex (Fig. 5(A)) in the IR spectra. This indicates that the chiral (salen) cobalt (III) complex (B) was successfully attached to Al-containing mesoporous Silicalite and ZSM-5

Catalytic activity in asymmetric synthesis. In Table 2, the activities of heterogeneous cataly sts synthesized newly in this work are summarized after examination for the asymmetric 

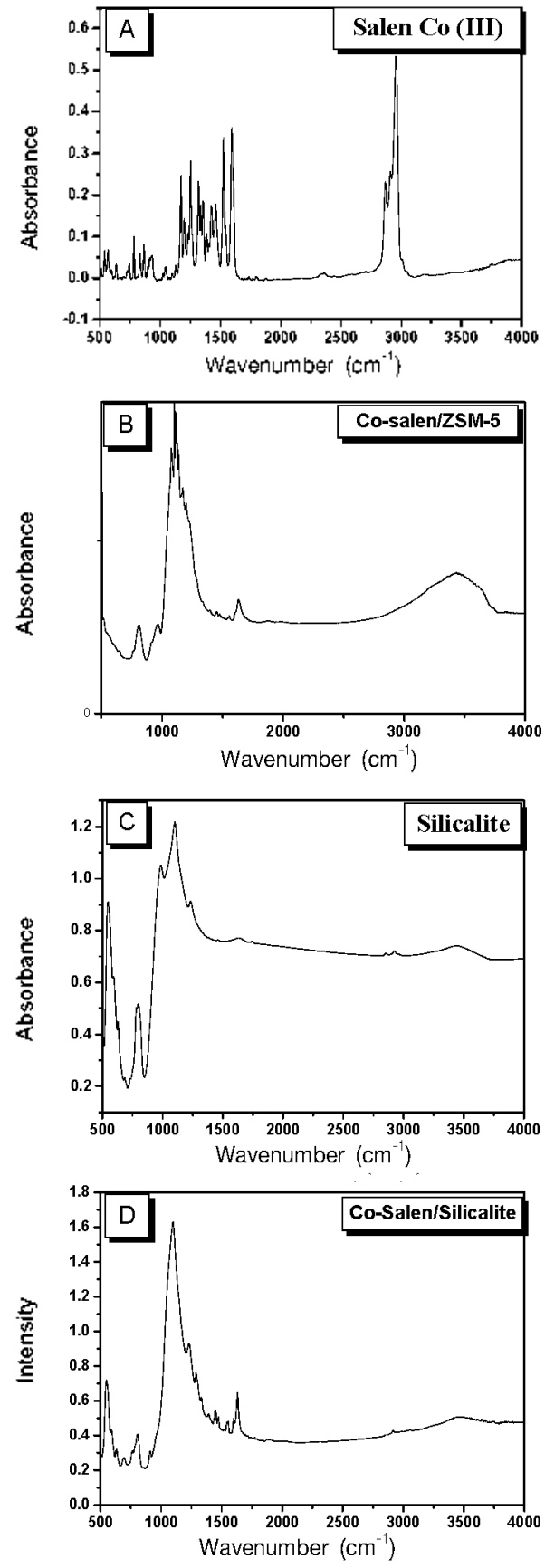

Figure 5. FT-IR spectra of (A) Co-salen complex; (B) Co-salen complex inmobilized on mesoporous ZSM-5: (C) pure mesoporous Silicalite obtained after $0.6 \mathrm{~g}-\mathrm{HF} /(\mathrm{g}$-zeolite) treatment; (D) Co-salen complex immobilized on mesoporous Silicalite (sample(Ci).

ring opening reaction of racemic epoxides by phenol derivatives. It is evident that the immobilized $\mathrm{Co}$ (III)-BF salen catalyst on mesoporous MFI-ty'pe zeolites exhibited the very high activity and selectivity. The scope of substrates was further explored using chiral (B) / mesoporous Al-loading MFI zeolite. and the most significant results are summarized in Table 2. As shown in Table 2, the enantioselective ring opening reaction of epoxides was found to be applicable for the synthesis of enantiopure phenoxy compounds using phenol derivatives as nucleophiles. 3-Chlorophenol (3-CP) acts as an excellent nucleophile for the kinetic resolutions of
Table 2. Asymmetric ring opening of teminal epoxides with phenol derivatives catalyzed by Co-salen complex $(\mathbf{B})$ immobilized on mesoporous MFI-type zeolite.

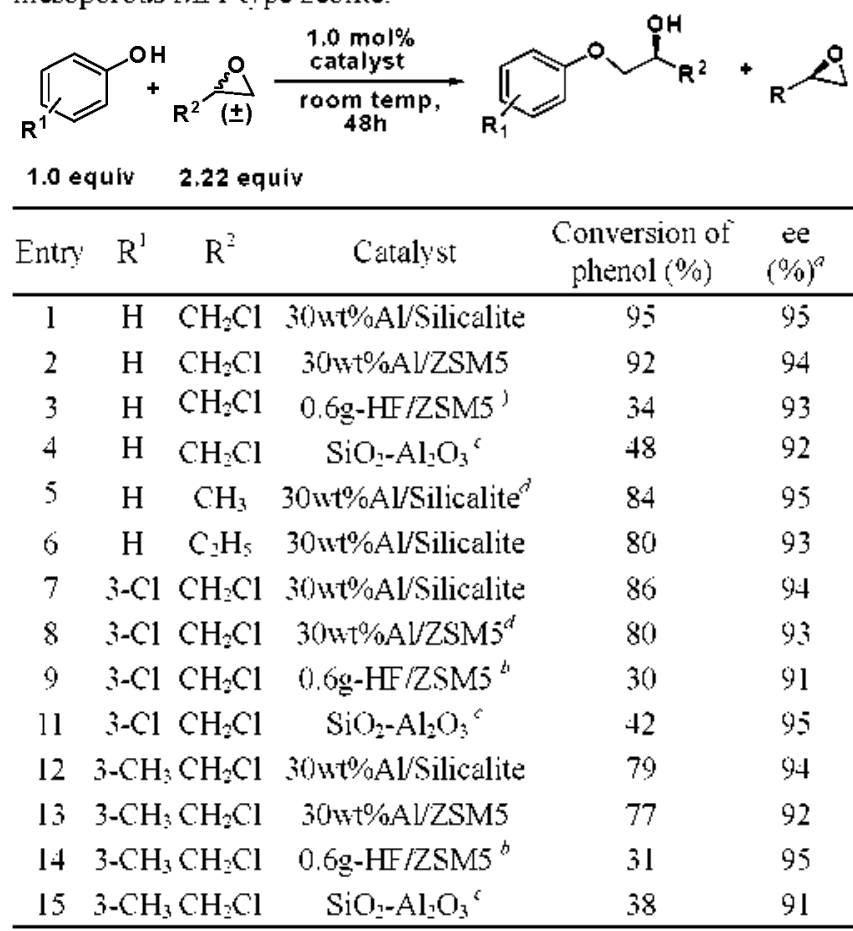

"ee "o was determined by chiral HPLC and chiral GC. Products were characterized by ${ }^{1} \mathrm{H}$ and ${ }^{13} \mathrm{C}$ NMR and found to be similar to that reported. ${ }^{13-1+}$ "The $0.6 \mathrm{~g}-\mathrm{HF}$ treated ZSM- 5 itself was used as a support to immobilize the Co-salen complex (B) without loading of aluminium. " $\mathrm{SiO} \mathrm{O}_{2}-\mathrm{Al}_{2} \mathrm{O}_{3}$ was purchased from Aldricl $\mathrm{Co}$. The catalyst 30 ut?:0 Al:ZSM5 means $30 \mathrm{ut}^{\circ}: \mathrm{i}$ aluminium loaded atter $0.6 \mathrm{~g}$-HF g-zeolite treatment. In all cases. Corsalen complex (B) was used for immobilization. Catalyst loading was fixed as $1.0 \mathrm{~mol}^{\circ}$ based on $\mathrm{Co}$-salen relative to phenol.

$\mathrm{ECH}$. Overall. phenols used in this work for the ring opening of epoxides exhibited a good yield and ee's. Optically active $\mathrm{ECH}$ with up to $95 \%$ enantiomeric excess was obtained in high y ield.

To observe the trends in the activity and enantioselectivity of chiral cobalt-salen complexes immobilized on mesoporous ZSM-5 and Silicalite as supports. the reactivities of the homogeneous and heterogenized chiral (salen) $\mathrm{Co}_{-}-\mathrm{BF}_{2}$ complexes were examined in the kinetic resolution of $( \pm)-E C H$ with phenol with a prolonged reaction time. Fig. 6 shows that the ring of terminal epoxides was opened enantioselectively by the phenol in the presence of heterogenized chiral Co(III) salen complexes. When the complex (B)/meso Silicalite was used as the catalyst. the reaction proceeded smootlly at room temperature and provided excellent enantioselectivity up to $95 \%$ ee in good yield. In conparison, the homogeneous Co-salen complex (B) exhibited the almost same catalytic activities relative to $(\mathbf{B}) /$ meso Silicalite as shown in Fig. 6 . It is remarkable that salen (B)/HZSM-5 (parent material before $\mathrm{HF}$ treatment) has no activity in this reaction. showing that the homogeneous Co-salen conplex (B) was not loaded on the microporous ZSM-5 zeolite without mesopores. Because MFI-type zeolite has only the microporous pore channel. it is impossible to immobilize the large salen molecules inside the crystals.

In comparison. pure macroporous $\mathrm{SiO}_{2}-\mathrm{Al}_{2} \mathrm{O}_{3}$ support was 
used to anchor the same type of salen complexes. However. with the chiral salen complex $(\mathbf{B}) / \mathrm{SiO}_{3}-\mathrm{Al}_{z} \mathrm{O}_{3}$ catalyst. a lower catalytic activity was obtained even after the prolonged reaction time. This result indicates that the three dimensional mesoporosity of supports gave an important role in the catalysis. The mesoporosity may provide the high probability that any salen catalyst in the pore can interact with other catalyst.

The effect of loading amount of salen catalysts on the reactivity was tested in detail by using the chiral catalyst (B)/meso MFI zeolite having the different loading content of aluminum, and the results are summarized in Fig. 7. Higher rates of reaction were observed, when the high concentration of active sites (salen complex (B) molecules) was allowed on the same amount of supports. The anchored amount of salen complex (B) was proportional to that of $\mathrm{Al}$ present on the supports. The attached contents of Co-salen complex (B) were $3.6,7.1$ and 9.5 wt \% over 10,20 and $30 \mathrm{wt} \%$ Al-loaded mesoporous Silicalite, respectively. The reaction with catalyst 30 wt $\%$-Al/mesoporous Silicalite led to $95 \%$ conversion of phenol after $48 \mathrm{~h}$. Whereas $10 \mathrm{wt} \%$-Al/mesoporous Silicalite showed a lower reaction rate even though the total number of salen unit added into the reaction mixture was controlled to be same as $1.0 \mathrm{~mol} \%$ salen relative to a reactant (phenol). This result gives a strong support to a cooperative bimetallic mechanism involving a simultaneous activation of both epoxide and nucleophile by different cobalt-salen units. The remarkable correlation between the reaction rates and the population of salen cataly'sts on the support was evident from the result of catalysis.

Recyclability of chiral Co(III) salen complexes anchored on the mesoporous MFI-zeolite was investigated in the same
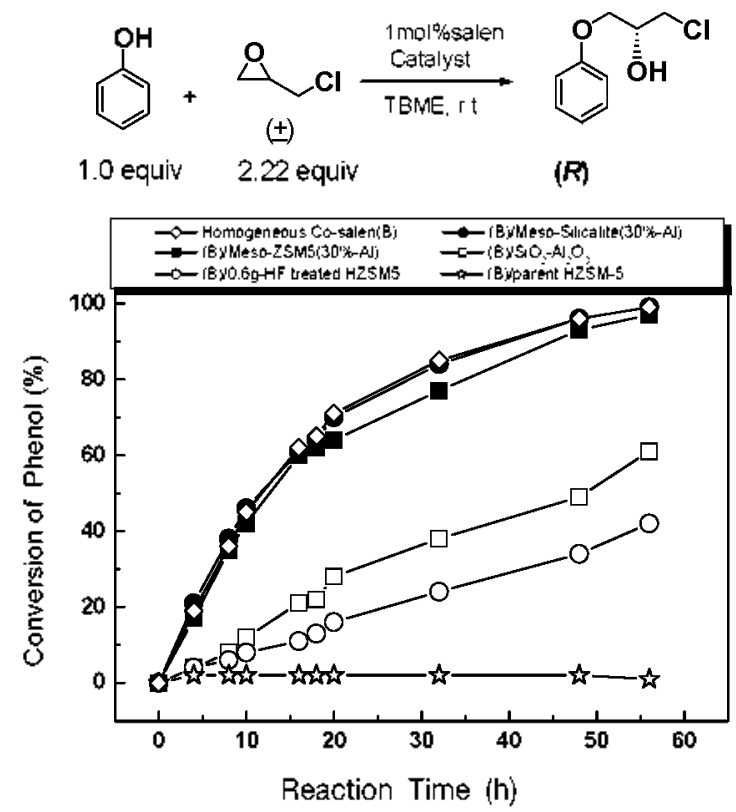

Figure 6. The catalytic activity of heterogeneous catalysts in the ring opening of ( \pm )-ECH with phenol (In the case of (B)/MesoSilicalite and $(\mathbf{B}) /$ Meso-ZSM5, 30wt $\%$ of aluminium was loaded on the support after $0.6 \mathrm{~g}-\mathrm{HF} /(\mathrm{g}$-zeolite) treatment, respectivelv. For catalysts of $\square, \triangle,-$ Co-salen complex (B) was anchored without loading of aluminum on the support.)
Talble 3. Recrclability of chiral Co(III) salen complexes(B) immobilized on mesoporous Silicalite after HF-treatment and 30 wt $\%$ Al-loading.

\begin{tabular}{|c|c|c|c|c|c|c|}
\hline $\mathrm{R}_{1}$ & & $\mathrm{H}$ & & & $3-\mathrm{Cl}$ & \\
\hline Recycle times & lst & $2 n d$ & $3 \mathrm{rd}$ & lst & 2nd & ind \\
\hline Conversion $(\%)^{a}$ & 95 & 92 & 93 & 86 & 84 & 84 \\
\hline ee $(\%)$ & 95 & 93 & 91 & 94 & 92 & 91 \\
\hline
\end{tabular}

${ }^{a}$ The conversion was determined by GC. "The catalyst was used without further regeneration.

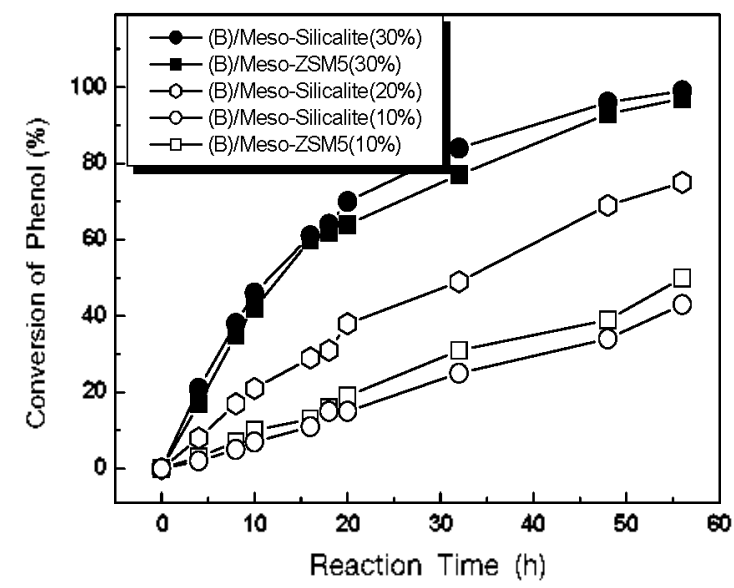

Figure 7. The effect of loading amount of Al added to the support for immobilization of the salen complex $(\mathbf{B})$ on the catalytic activity in the ring opening reaction of racemate $\mathrm{ECH}$ by phenol (The nimber in the parenthesis means the contents of aluminium $\%$ on the support, and $0.6 \mathrm{~g}-\mathrm{HF} /(\mathrm{g}$-zeolite) treatment was applied before Al-loading).

reactions as mentioned above. The catalyst was collected by simple washing with MC. THF solvent for reuse after completion of reaction. The catalyst could be recycled without regeneration, as summarized in Table 3 . After three times recycle. heterogenized salen catalysts retained the high catalytic activity, but the very low decrease in enantioselectivity was found by repeated use. indicating no severe extraction of salen complex from the support and no deactivation of active site during the repeated use.

\section{Conclusion}

The HF-treated MFI-zeolite resulted in formation of mesopores (mean pore size: $2.5-3.5 \mathrm{~nm}$ ) in the microporous crystal. The chiral salen calbalt(III) complexes were successfully immobilized in the mesopores of MFI-zeolites by noncovalent method. The formation of mesopores and the immobilization of Co-salen complex in MFI-zeolite could be confirmed by the instrumental analysis. The newly synthesized chiral catalysts showed high activity and enantioselectivity in the phenolic ring opening of terminal epoxides. Optically active $\alpha$-aryloxy alcohol compounds with up to $95 \%$ enantiomeric excess was obtained in high yield. 
Acknowledgments. This research was supported by Research grant of Inha Technical College in 2007.

\section{References}

1. Collman, J. P.; Wang, Z: Straumanis, A.; Quelquejeu, M.; Rose, E.J.Am. Chem Soc. 1999,121, 460

2. Hanson, R. M. Chem Rev 1991, 91, 437.

3. Tokunaga, M.; Lanrow, J. F.: Kakiuchi, F.; Jacobsen, E. N. Science 1997, 277, 936 .

4. Nielson, L. P. C.; Stevenson, C. P, Backmond, D. G.: Jacobsen, E. N. J. Am. Chem. Soc. 2004, 126, 1360 .

5. Soai, K.; Watanabe, M; Yamamoto, A. J. Org. Chem 1990, $55,4832$.

6. Kim, S. W.: Bae, S. T.; Hyeon, T.: Kim, B. M. Afrcro. Weso. Water $2001,44,523$

7. Konsler, R. G.: Karl, T. Tacobsen, E. N. J. Am. Chem. Soc. 1998 , 120,10780

8. Breinbauer, R. Jacobsen, E. N. Angew: Chem. Int. Ed 2000, 39, 3604.

9. Kwon, M.: Kim, G.-I. Catalvisis Today 2003, 87, 145 .
10. Annis, D. A.; Jacobson, E. N. J.Am. Chem. Soc 1999, 121, 4147.

11. Shin, I.-H.: Kim, G.-J. Tetrahedron Letters 1999, $\$ 0.6827$.

12. Penkert, S., Jacobsen, E. N. Org. Lett. 1999, 1, 1245.

13. Schuster, C.; Holderich, W. F. Catalvsis Todav 2000, 60, 193.

14. Ogurwumi, S. B: Bein, T. Chent. Conmm 1997, 901 .

15. Groen, J. C.: Bach, T.; Ziese, U.; Paulaime-van Donk, A. M:; De Tong, K. P : Moulijn, J. A.; Perez-Ramirez, J. J. Am. Chent. Soc. $2007,127,10792$.

16. Groen, J. C.: Hamminga, G. M.: Moulijn, J. A.: Perez-Ramirez, J. Phys. Chem. Chem. Phys. 2007, 9, 4822 .

17. Groen, J. C.; Tansen, J. C.; Moulijn, J. A.; Perez-Ramirez, J. $J$. Phus Chem. B 2004, 109, 13062 .

18. Cejka, J; Mintova, S.J. Catal. Rev, 2008, +9, 457.

19. Mintova, S. T.; Cejka, T. Stud. Suf. Sci. Catal. 2007, 168, 301.

20. Lee, K. Y.: Kawthekar, R. B.: Kim, G.-J. J. Korean Ind Eng. Chem 2007, 18,330.

21. Yoon, S. B.; Solur, K; Kim, J. Y; Shin, C.-H.; Hyeon, T. Ad Mater. $2002,1+19$

22. Gan, J.; Wang, T.; Liu, Z.; Tan, W. Stud. Suf. Sci. Catal. 2007, $170 B, 1567$. 